\title{
Residencia: La memoria de Chile está en el mar. Instalación sonora
}

Ana María Estrada, artista visual y sonora U. de Chile / U. de Barcelona cerosilencio@gmail.com

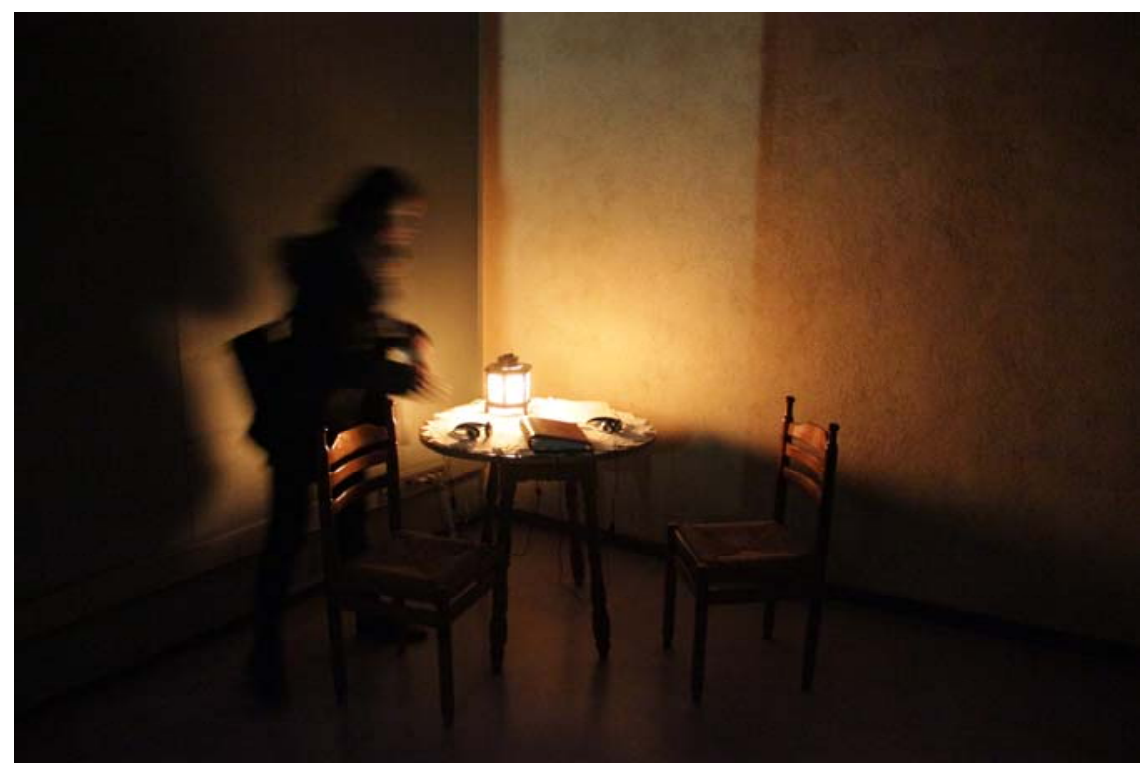

Todas las fotografías de La memoria de Chile está en el mar son de Luis Alanis, 2015.

El proyecto La memoria de Chile está en el mar fue presentado en el Convento de San Agustín de Barcelona, como parte del Festival Vértex, el año 2015. La instalación se configuró de la siguiente manera: sobre una mesa ubicada en una sala iluminada por la tenue luz de una lámpara, había un álbum fotográfico sin fotos y dos pares de cascos conectados a él. Junto a la mesa, se colocaron dos sillas, para que el público pudiera sentarse a hojear el álbum. La sala estaba inundada por el sonido del mar. Si bien el álbum estaba vacío, bajo cada espacio donde debía ir una imagen estaba registrado el nombre completo de una persona. A través de los cascos, se escuchaba una voz narrar brevemente la historia de algún amigo o pariente, cómo recordaba su vida y qué día le había dejado de ver. Las personas de las que se hablaba habían sido detenidas y desaparecidas durante la dictadura chilena de 19731990. Estos relatos corresponden a cápsulas radiales generadas por el proyecto http://loslatidosdelamemoria.cl, de las psicólogas Karen Bascuñan y Paulina Pavez. 
Ana María Estrada. Residencia: La memoria de Chile está en el mar. Instalación sonora.

La relación entre sonido y memoria, que he explorado en diversas propuestas, se torna aún más pertinente de explicitar en esta instalación, puesto que, al ser elaborada desde la distancia, la memoria se despliega, en cierta medida, en la dimensión del recuerdo.

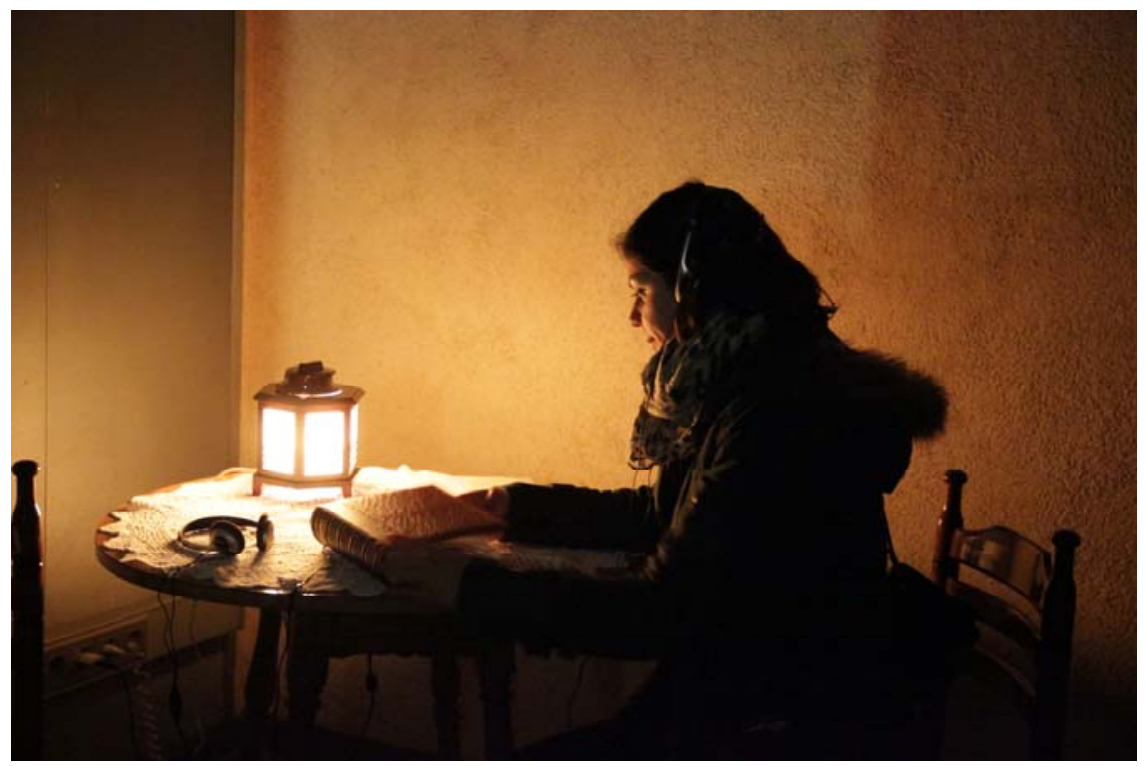

Quizá habría que decir que los recuerdos se distribuyen y se organizan en niveles de sentido o en archipiélagos separados posiblemente mediante precipicios, y que la memoria sigue siendo la capacidad de recorrer

y de remontar el tiempo, sin que nada en principio pueda impedir que continúe sin solución de continuidad ese movimiento.

Paul Ricoeur 
La dimensión temporal que implica la memoria es relevante para la dimensión temporal que involucra normalmente el trabajo con el sonido, pues, como bien señala Michel Chion, "el sonido no relata el tiempo de su duración. Relata -o no relata- otro tiempo, e incluso, en ciertos casos, la misma ausencia de tiempo". El sonido tiene la capacidad de reconstituir el tiempo, en tanto el sujeto que escucha entra y sale de un presente al que puede volver a ingresar sin perder el sentido, aun cuando lo escuchado sea ya un pasado, porque logra hilvanar un recorrido no necesariamente lineal, pero que sí es continuo, puesto que el individuo que escucha se vuelve consciente -reflexiona y recuerda- que ha estado escuchando (en el pasado).

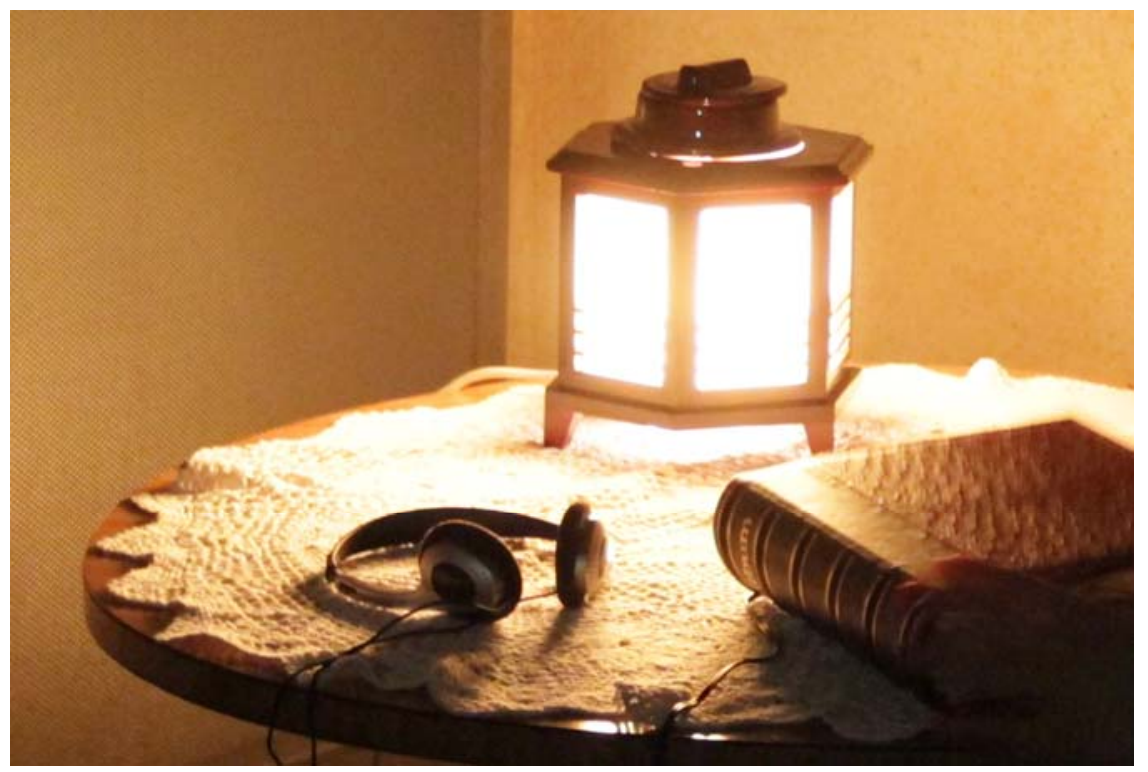

Si reflexiono y, durante este tiempo, dejo de oír, en el momento en que vuelvo a tomar contacto con los sonidos, se me aparecen como ya ahí, encuentro un hilo que había soltado y que no está roto.

Maurice Merleau-Ponty 
Ana María Estrada. Residencia: La memoria de Chile está en el mar. Instalación sonora.

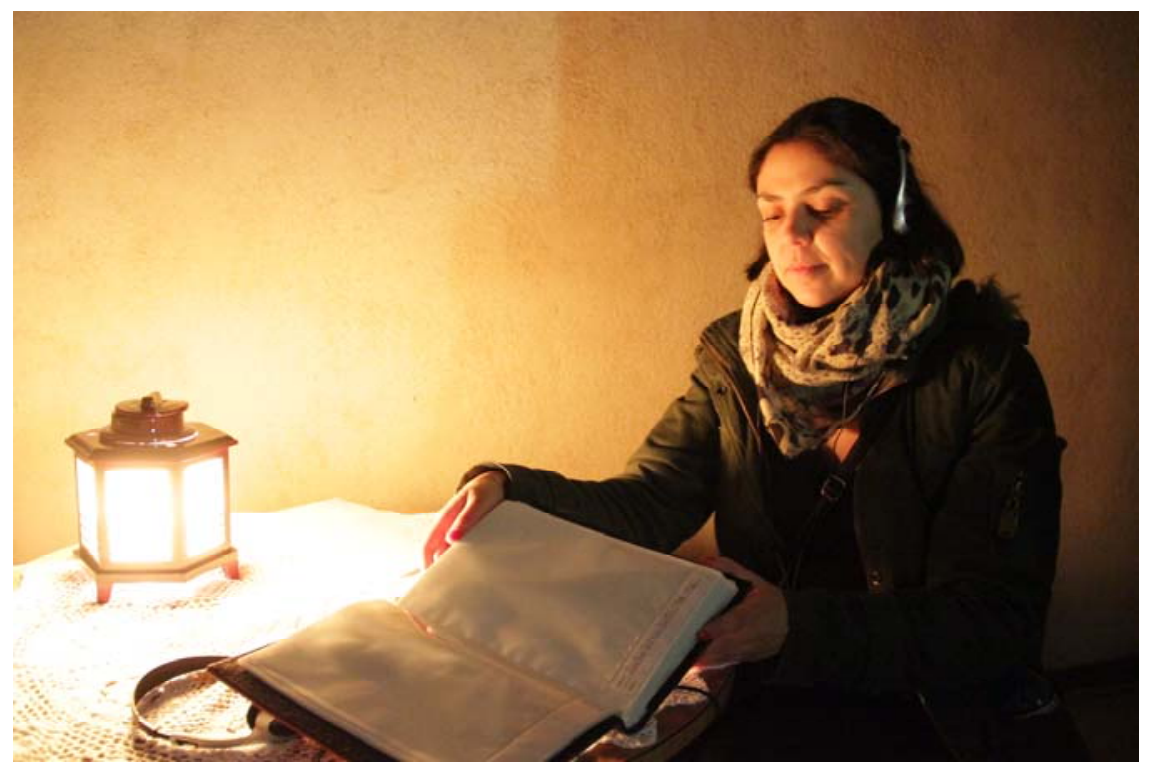


Uno de los objetivos centrales de la instalación fue intentar restaurar una parte de la historia de mi país que aún permanece silenciada, porque su "conocimiento" no ha contado con el suficiente re-conocimiento. El sonido, en ese contexto, se usó como una herramienta estética que permite insistir en relatos que precisan ser reiterados, para que su recuerdo contribuya a la conformación de una memoria que sólo se ha construido a tientas y requiere ser dicha y escuchada en el tiempo. Señalo el mar como lugar geográfico en el cual podríamos encontrar parte de esa memoria, debido a la gran cantidad de cuerpos de personas vivas y muertas que fueron arrojados en nuestro océano Pacífico durante la dictadura y sobre los cuales el ejército chileno nunca ha dado información certera. Además, la marca sonora del mar señala un territorio específico, subrayando mi distancia geográfica con él, y busca guiar a la audiencia a un estado reflexivo. De esta manera, lo que buscaba con esta instalación era generar una instancia para la memoria, más allá de tan sólo reflejar una realidad. 
Por último, los elementos no se dispusieron para que el espectador contemplase un altar, sino para que se acercara a él y lo habitara por medio de la escucha, desde una relación de identidad. En efecto, se invitaba al público a habitar una memoria que no era necesariamente la suya, sino que era mía, pues se trataba de la memoria de Chile. Más allá de la nostalgia, la distancia con mi país radicalizó en mí la necesidad y la urgencia de mantener en nuestra y en mi memoria a todas esas personas desaparecidas y muertas bajo uno de los períodos más oscuros de Chile. Esto, a su vez, podría redundar en una pregunta por la historia propia del público para el que se presentaba este trabajo, considerando que una de las dictaduras más extensas que ha habido es la de Francisco Franco, desarrollada en España entre los años 1939 y 1975.

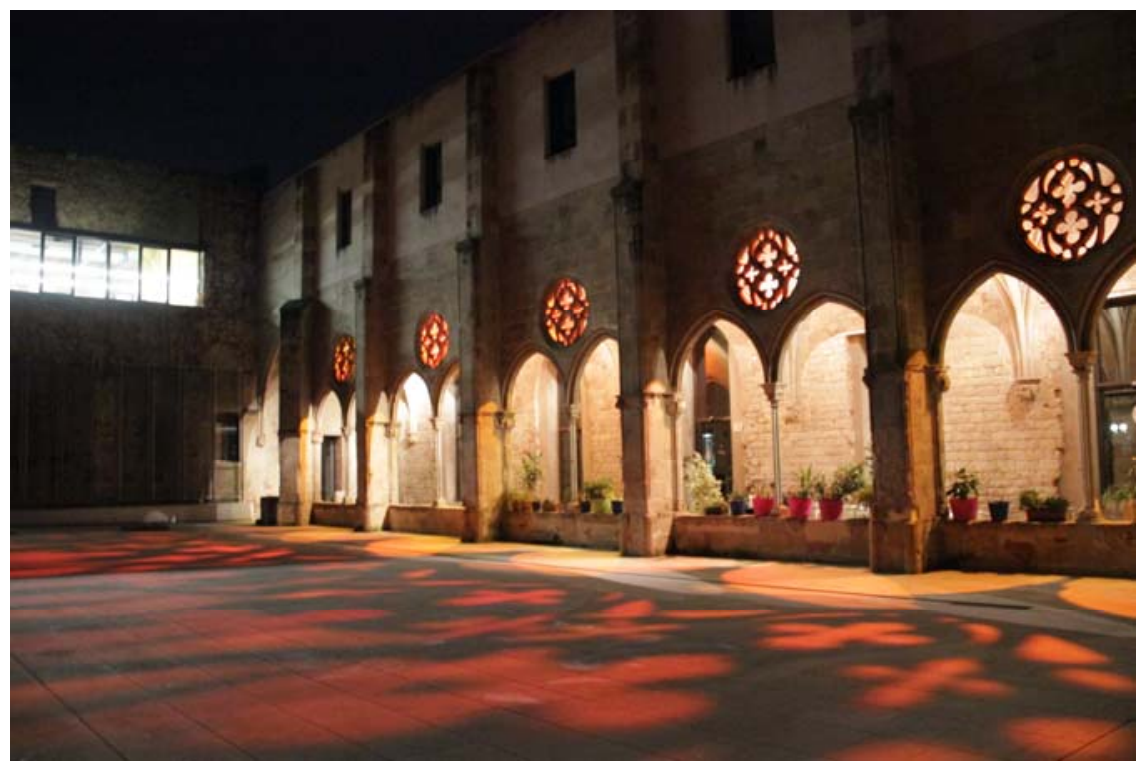

Convento de San Agustín en Barcelona. 